\title{
Congenital Coronary Variants and Anomalies: Prevalence in Cardiovascular Multislice Computed Tomography Studies in a Single Center
}

\author{
Catarina A. Oliveira1, Paula Mota' ${ }^{2}$, Susana P. Basso'1, Rui P. Catarino1 \\ ${ }^{1}$ Medical Imaging Department, Faculty of Medicine, University Hospital of Coimbra, Coimbra, Portugal \\ ${ }^{2}$ Cardiology Department, General Hospital, University Hospital of Coimbra, Coimbra, Portugal \\ Email: Kat.catarina@gmail.com
}

Received 14 March 2014; revised 14 April 2014; accepted 21 April 2014

Copyright (C) 2014 by authors and Scientific Research Publishing Inc.

This work is licensed under the Creative Commons Attribution International License (CC BY). http://creativecommons.org/licenses/by/4.0/

(c) (i) Open Access

\begin{abstract}
In the era of Multislice Computed Tomography (MSCT), few studies have been dedicated to the evaluation of coronary anomalies and variants. We aim to present, describe and assess the prevalence of congenital coronary variants and anomalies (CVA) in the MSCT coronary angiographic studies performed in our department. All the MSCT coronary angiographies performed in our department, between April 1, 2007 and May 31, 2012 were reviewed. Coronary anomalies and variants were characterized and grouped according to their type: origin, course (including myocardial bridging) and distal ending. A total of 663 patients underwent a MSCT coronary evaluation during this period. A total of 84 anomalies and variants were identified in 80 individuals: $12.1 \%$ of the population $(80 / 663)$. The most frequent variant was the myocardial bridging of the anterior descending artery. Four $(4.7 \%)$ of the anomalies were considered malignant, corresponding to a prevalence of $0.6 \%(4 / 663)$ in the population. Congenital coronary anomalies and variants are relatively common. In our study, the prevalence was $12.1 \%$, myocardial bridging being the most common. This fact may explain the higher prevalence compared to some series based on the cardiac catheterization studies. Few of these anomalies were considered malignant, with prevalence rates similar to those found in the cardiac catheterization studies.
\end{abstract}

\section{Keywords}

Coronary Angiography, Congenital Anomalies, Diagnosis, Epidemiology, Imaging, Computed Tomography 


\section{Introduction}

The normal coronary anatomy includes the left coronary artery or left main stem (LC) that arises from the left coronary sinus and the right coronary (RC) artery arising from the right coronary sinus. The left coronary artery usually bifurcates into the left anterior descending artery (LAD) (providing septal and diagonal branches) and the circumflex coronary artery (LCx) (providing marginal obtuse branches); sometimes a third branch-the intermediate or ramus branch can be identified. The RC artery gives rise to a pulmonary cone branch, a sinusal node branch and marginal branches. In approximately 85\% of cases, the RC artery is dominant and passes along the posterior atrioventricular groove, leading to the posterior descending artery and at least one posterolateral artery [8] (Figure 1 and Figure 2).

There are some studies exploring the prevalence and characteristics of coronary variants and anomalies (CVA), but most of them are based on cardiac catheterization studies [1]-[5]. MSCT coronary angiography has proven to be effective not only in the identification and characterization of coronary artery disease, but also in the evaluation of the anatomical coronary details [6] [7]. The aim of this study was to evaluate the prevalence and characteristics of coronary variants and anomalies (CVA) in the MSCT studies performed at our department.

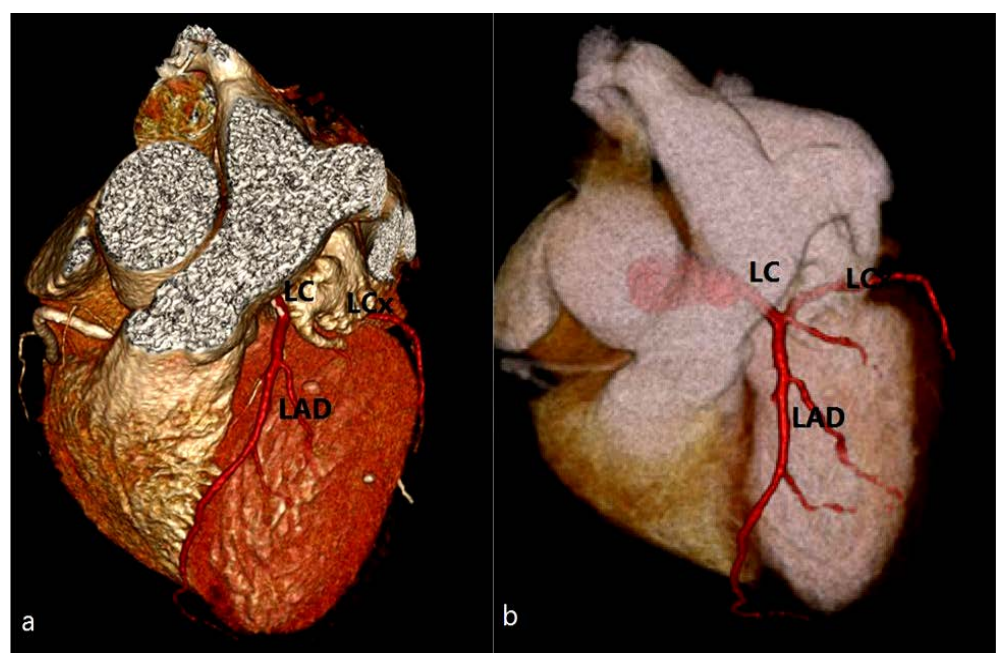

Figure 1. Volumetric reconstruction showing the left coronary normal anatomy (LC-Left coronary; LCx-Left circumflex artery; LAD-Left anterior descending).

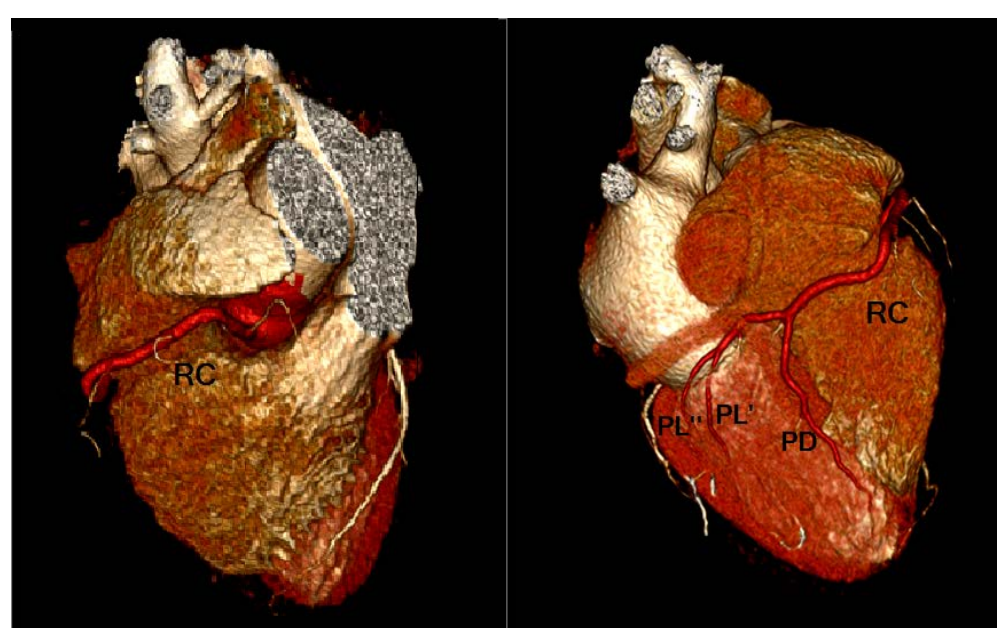

Figure 2. Volumetric reconstruction showing the right coronary artery normal anatomy (RC-Right coronary; PD-Posterior descending; PL-Postero-lateral branch). 


\section{Methods}

A retrospective study was conducted based in all MSCT coronary angiography performed in our department during the period from April 1, 2007 and March 31, 2012. Coronary artery disease screening in patients with low or intermediate risk and atypical chest pain, questionable stress test or contradictory results in previous cardiac studies was the clinical indication for performing MSCT angiography. Severe renal disease, documented contrast allergy, pregnancy, uncontrolled heart beat rate (greater than 70 beats/minute) and inability to perform apnea for at least 10 - $12 \mathrm{~s}$ were contraindications for the MSCT angiography.

In each study, all patients received a sublingual vasodilator (5 mg isosorbide dinitrate). In patients with a heart rate greater than 60/70 pulses/minute, a beta-blocker was orally administered (50 mg metoprolol or atenolol 100 $\mathrm{mg})$. Heart rate and blood pressure were monitored in all patients.

The MSCT angiographical studies were performed with a 64-slices (AS 64 Somaton Definition, Siemens Medical Solutions, Erlangen, Germany) and 16-slices (Brilliance 16 CT Scanner, Philips Healthcare, USA) equipment. The acquisition was ECG-synchronized. In most cases, an initial prospective pre-contrast acquisition for calcium score evaluation was performed, followed by a post-contrast retrospective acquisition with dose modulation. The following acquisition parameters were used: tube voltage $120 \mathrm{kV}$ and tube current 20 - $600 \mathrm{~mA}$; in 64-slice MDCT a collimation of $0.6 \mathrm{~mm}, 0.33$ seconds per rotation and 0.2 pitch was used, and in the 16-slice MDCT a collimation of $0.75 \mathrm{~mm}, 0.5$ seconds per rotation and 0.2 pitch.

In all studies, 80 - 100 cc of intravenous contrast (Ultravist ${ }^{\circledR} 370$ (Bayer Healthcare)-Iopramida $370 \mathrm{mg} \mathrm{I} / \mathrm{ml}$ ) at a flow of $4 / 5 \mathrm{ml} / \mathrm{s}$ was administered. The studies were performed in inspiratory apnea.

Imaging analysis was performed in Cardiac Viewer ${ }^{\circledR}$ (Phillips Healthcare Products, USA) and Vitrea Advanced $^{\circledR}$ (Toshiba Medical Systems, Japan). Coronary arteries were evaluated on axial images, multiplanar reconstructions (MPR), maximum intensity projection (MIP) and volumetric reconstructions. Reconstructions were mainly preformed using a diastolic phase (60\% to $70 \%$ R-R interval), in order to obtain a higher coronary volume and lower cardiac motion artifact.

All coronary anomalies and variants were characterized, and grouped according to their type. A simplified anatomic classification that divides anomalies in three main groups: origin, course and (distal ending) termination variants or anomalies, and its subtypes [8]-[10] was used (Table 1). CVA associated with a higher risk of sudden death (malignant), were better characterized due to their greater clinic relevance.

Prevalence results are presented in absolute number and percentage.

\section{Results}

During this period, 663 patients underwent coronary MSCT angiographic study. Coronary anomalies or variants

Table 1. Coronary anomalies and variants classification (adapted from Kim et al.).

\begin{tabular}{c} 
Origin \\
High origin \\
Multiple ostia \\
Single coronary artery \\
Pulmonary origin \\
Contralateral or non coronary sinus origin with a anomalous course (retroaortic, interarterial, prepulmonary, septal) \\
Course \\
Myocardial bridging \\
Duplication \\
Distal ending \\
Fistula \\
Arcade \\
Extracardiac \\
\hline
\end{tabular}


were found in 80 patients, 50 women and 30 men, with a mean age of 65, 4 years (range 20 - 85 years). In 4 cases, two CVA were found in the same patient, in all of them at least one of the CVA was a myocardial bridging.

The distribution of CVA is described in Table 2.

Most of the CVA were course type CVA. They were identified 64 cases of miocarddial bridging (Table 3) in 62 patients. The majority located in the middle and distal segments of the LAD artery (Figure 3). Two patients had two distinct myocardial bridging in different arteries and two patients had a myocardial bridging and a concomitant coronary origin abnormality. In one patient, there was identified a LAD duplication (Figure 4).

Some origin abnormalities were identified (Table 4): three cases of high arterial origin (Figure 5), three cases of multiple ostia - two separate origin of the LAD and LCx (Figure 6) and a case of an obtuse marginal artery originating directly from the coronary sinus, six contralateral sinus origin with anomalous course (Figure 7 and

Table 2. Coronary variants and anomalies distribution by type and its prevalence.

\begin{tabular}{ccccc}
\hline Type & Number & Percentage & Patients & Prevalence \\
Course & $65^{*}$ & $77.4 \%(65 / 84)$ & $63^{*}$ & $9.5 \%(63 / 663)$ \\
Origin & 14 & $16.7 \%(14 / 84)$ & 14 & $2.1 \%(14 / 663)$ \\
Distal ending & 5 & $5.9 \%(5 / 84)$ & 5 & $0.8 \%(5 / 663)$ \\
Total & 84 & & $80^{* *}$ & $12.1 \%^{* *}(80 / 663)$ \\
\hline
\end{tabular}

${ }^{*}$ Two (2) patients with more than one course CVA; ${ }^{* *}$ Two (2) patients with more than one type CVA.

Table 3. Characterization and prevalence of coronary course variants and anomalies.

\begin{tabular}{|c|c|c|c|c|c|c|c|}
\hline & Artery & & & $\mathrm{Nr}$ & $\%$ & Patients & Prevalence \\
\hline \multirow{3}{*}{$\begin{array}{l}\text { Myocardial } \\
\text { bridging }\end{array}$} & LAD & $\begin{array}{l}\text { Medial } \\
\text { Distal }\end{array}$ & $\begin{array}{l}27 \\
29\end{array}$ & 58 & 89.2 & 58 & $8.7 \%(58 / 663)$ \\
\hline & Obtusal & $\begin{array}{l}\text { Medial } \\
\text { Distal }\end{array}$ & $\begin{array}{l}2 \\
1\end{array}$ & 3 & 4.6 & 3 & $0.45 \%(3 / 663)$ \\
\hline & Ramus & $\begin{array}{l}\text { Medial } \\
\text { Distal }\end{array}$ & $\begin{array}{l}2 \\
1\end{array}$ & 3 & $4.6 \%$ & 3 & $0.45 \%(3 / 663)$ \\
\hline Duplication & & LAD & & 1 & $0.6 \%$ & 1 & $0.15 \%(1 / 663)$ \\
\hline Total & & & & 65 & & $63^{*}$ & $9.5 \%(63 / 663)$ \\
\hline
\end{tabular}

${ }^{*}$ Two (2) patients with more than one course CVA.

Table 4. Characterization and prevalence of coronary origin variants and anomalies.

\begin{tabular}{|c|c|c|c|c|}
\hline Anomaly type & \multicolumn{2}{|c|}{ Artery } & $\mathrm{Nr}$ & Prevalence \\
\hline \multirow{2}{*}{ High origin } & \multicolumn{2}{|c|}{ Left coronary } & 1 & $0.15 \%(1 / 663)$ \\
\hline & \multicolumn{2}{|c|}{ Right coronary } & 2 & $0.3 \%(2 / 663)$ \\
\hline \multirow{2}{*}{ Multiple ostia } & \multicolumn{2}{|c|}{ LAD and LCx } & 3 & $0.45 \%(3 / 663)$ \\
\hline & \multicolumn{2}{|c|}{ Obtusal with proper origin } & 1 & $0.15 \%(1 / 663)$ \\
\hline \multirow{2}{*}{ Contralateral sinus origin } & Right coronary & Interarterial course & 4 & $0.6 \%(4 / 663)$ \\
\hline & $\mathrm{LCx}$ & Retroaortic course & 2 & $0.3 \%(2 / 663)$ \\
\hline Single artery & \multicolumn{2}{|c|}{ Right coronary sinus origin } & 1 & $0.15 \%(1 / 663)$ \\
\hline Total & & & 14 & $2.1 \%(14 / 663)$ \\
\hline
\end{tabular}




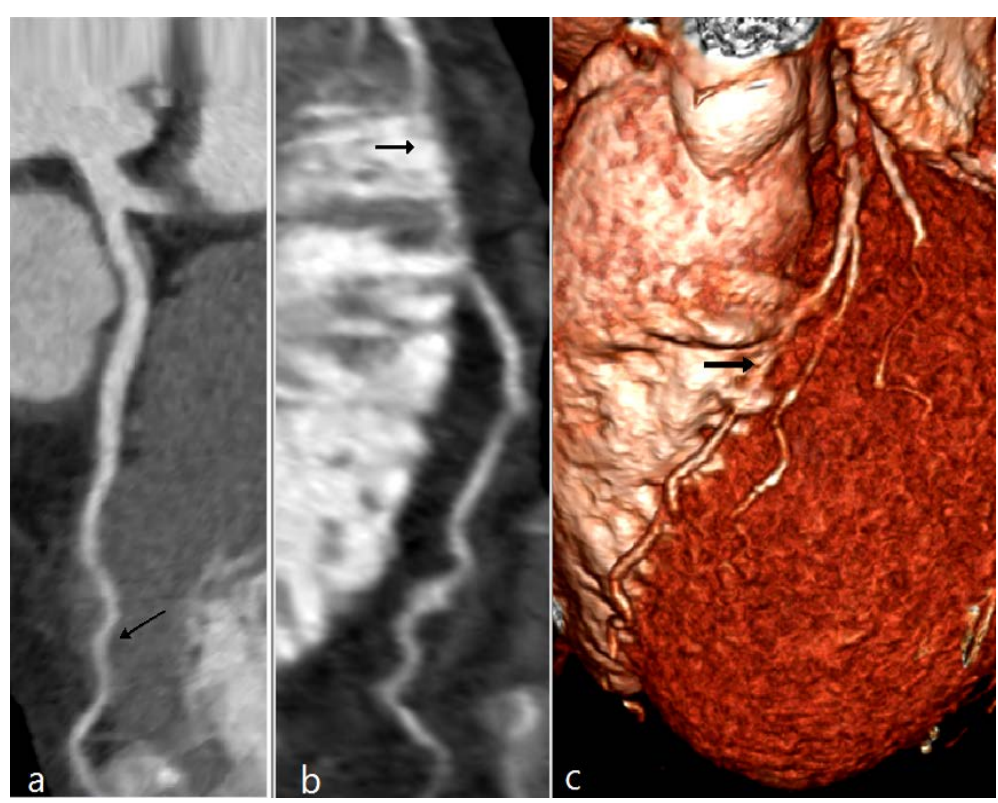

Figure 3. Multiplanar reconstruction (a) and (b) and volumetric reconstructions (c) showing myocardial bridging examples of the left anterior descending artery.

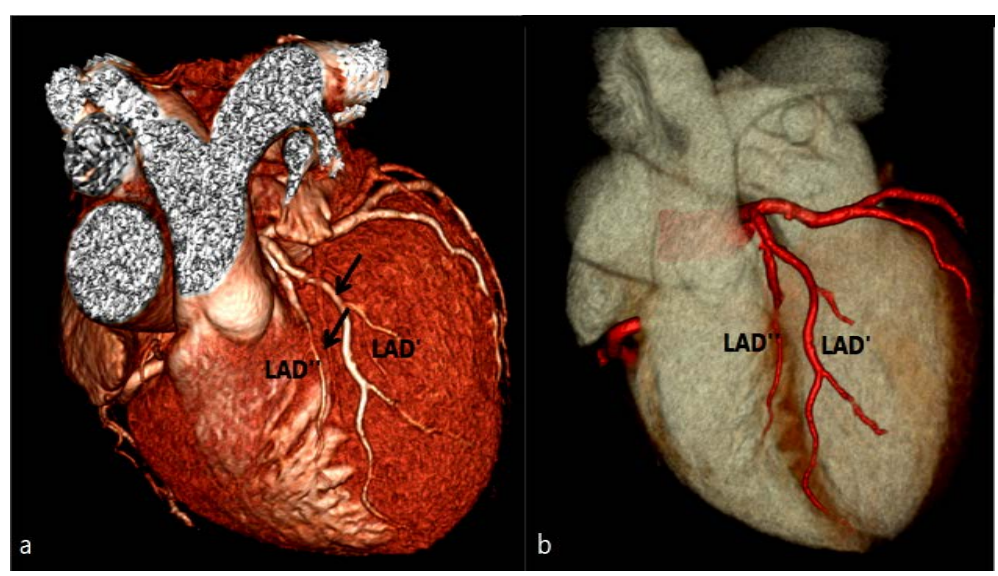

Figure 4. Volumetric reconstruction showing a left anterior descending duplication (arrows) (LAD-Left anterior descending).

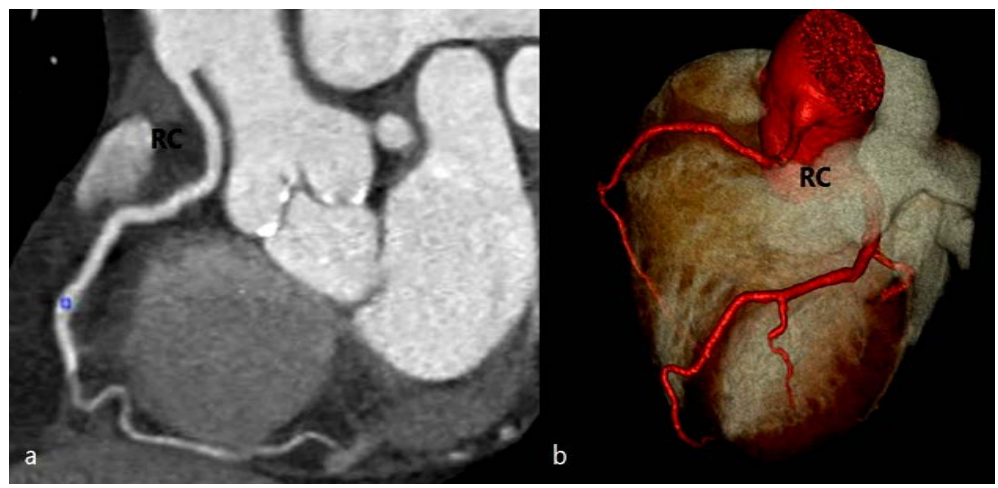

Figure 5. Multiplanar (a) and volumetric (b) reconstruction showing a high origin of the right coronary artery (RC-Right coronary). 


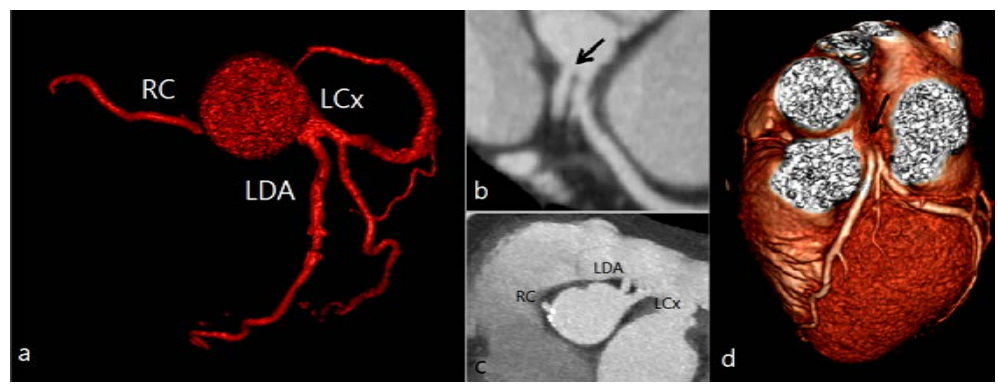

Figure 6. Volumetric (a) and (d) and multiplanar (c) and (d) reconstructions showing a separated origin of the LAD and LCx with two ostia (arrow) (RCright coronary; LCx-Circumflex artery and LAD-Left anterior descending).

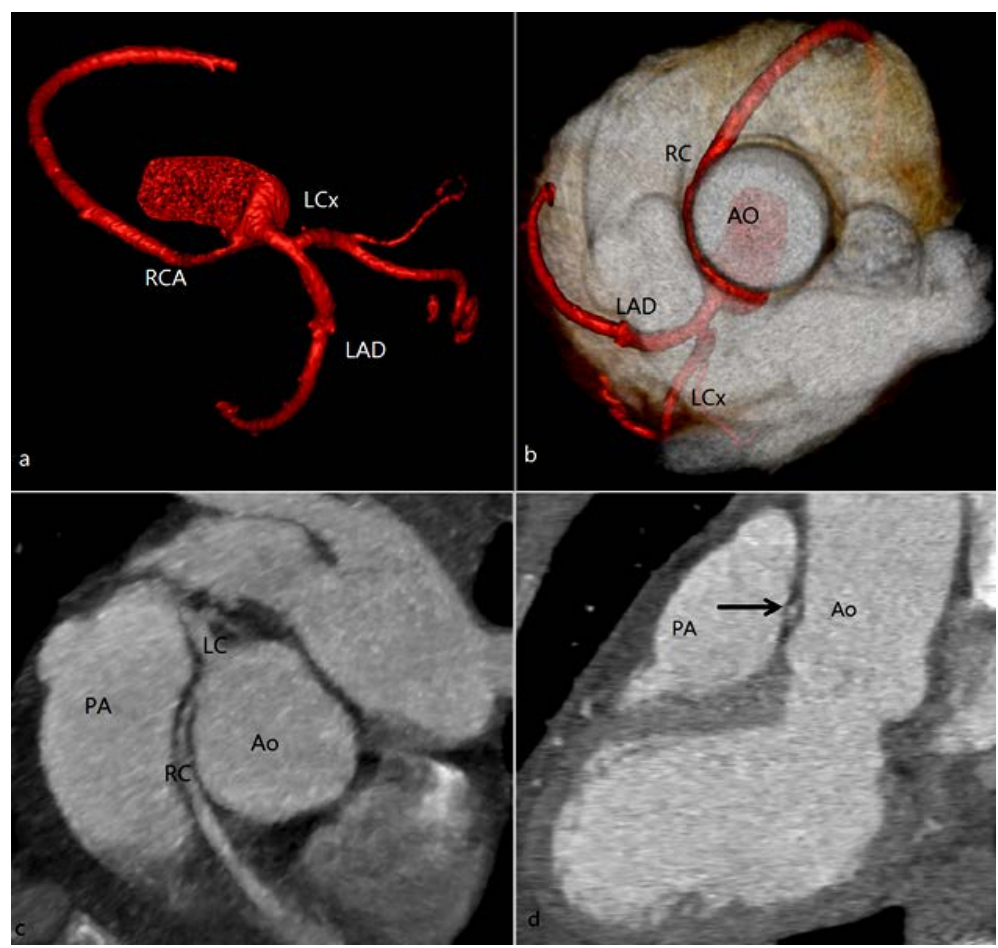

Figure 7. Volumetric (a) and (b) and multiplanar (c) and (d) reconstructions showing anomalous contralateral origin of the RC artery, with an interarterial course (arrow) (AO-Aorta; PA-Pulmonary artery; RC-Right coronary; LCxCircumflex artery and LAD-Left anterior descending).

Figure 8) - four cases with anomalous origin of the LCx artery and retroaortic coure and two cases of anomalous origin of the RC and interarterial course, and a case of single coronary artery originating from the right coronary (Figure 9).

Fistulas were the only distal ending abnormalities identified (Table 5). Most originating from the LAD and leading to the pulmonary trunk (Figure 10).

Four patients had malignant abnormalities: all due to an anomalous origin in the contralateral sinus with anomalous interarterial course (Table 6), corresponding to $0.6 \%$ prevalence in the population under study.

\section{Discussion}

The prevalence of CVA based in coronary MSCT studies varies widely in the literature from $2.69 \%$ to $24.5 \%$ [11]-[15]; in our study, prevalence was $12.1 \%(n=663)$ which is located within the limits of the values described. However, this value was larger than most series based on the cardiac catheterization studies, which 


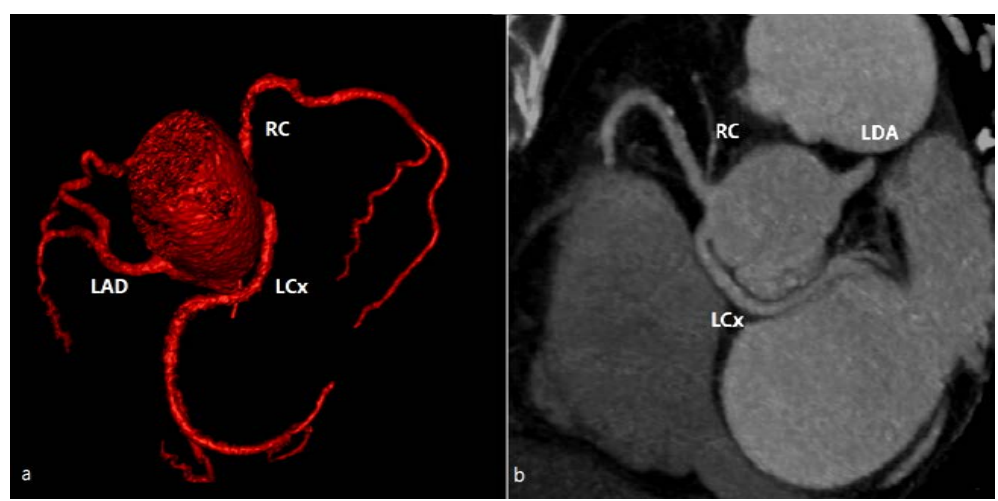

Figure 8. Volumetric (a) and multiplanar (b) reconstructions showing anomalous origin of the LCx artery in the contralateral sinus with a retroaortic course (arrow). (AO-Aorta; RC-Right coronary; LCx-Circumflex artery and LAD-Left anterior descending).

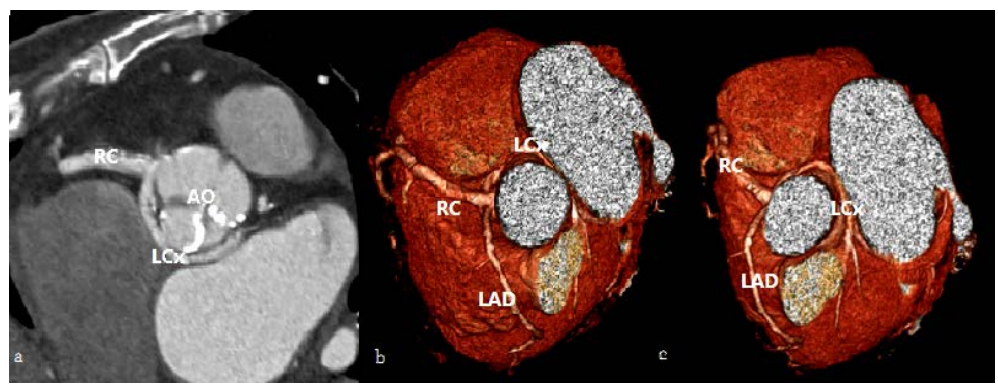

Figure 9. Multiplanar (a) and volumetric (b) and (c) reconstructions showing a single coronary artery with a right sinus origin (RC-Right coronary; LCxCircumflex artery and LAD-Left anterior descending).

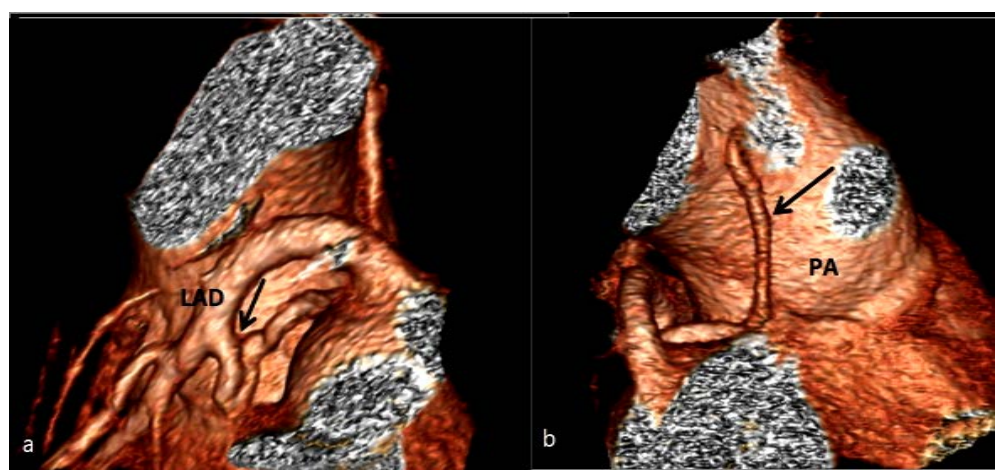

Figure 10. Volumetric reconstructions showing a LAD and pulmonary artery fistula (arrow) (PA-pulmonary artery and LAD-Left anterior descending).

Table 5. Characterization and prevalence of coronary distal ending variants and anomalies.

\begin{tabular}{|c|c|c|c|c|}
\hline & Artery & Communication & $\mathrm{Nr}$ & Prevalence \\
\hline & LAD & Pulmonary trunk & 3 & $0.45 \%(3 / 663)$ \\
\hline \multirow[t]{2}{*}{ Fistulas } & Right coronary & Right auricula & 1 & $0.15 \%(1 / 663)$ \\
\hline & RC, LCx and ramus & Pulmonary trunk & 1 & $0.15 \%(1 / 663)$ \\
\hline Total & & & 5 & $0.8 \%(5 / 663)$ \\
\hline
\end{tabular}


Table 6. Characterization of the malignant coronary anomalies.

\begin{tabular}{ccccc}
\hline & $\# 1$ & $\# 2$ & $\# 3$ & $\# 4$ \\
\hline Type & Origin & Origin & Origin & Origin \\
Characteristic & Contralateral sinus & Contralateral sinus & Contralateral sinus & Contralateral sinus \\
Artery & Right coronary & Right coronary & Right coronary & Right coronary \\
Course & Interarterial & Interarterial & Interarterial & Interarterial \\
Dominant & Yes & No & Yes & No \\
Plaques & No & No & Yes & 68 \\
Age (years) & 20 & 79 & 70 & F \\
Gender & M & F & No & No \\
Symptomatic & No & Yes & & . \\
\hline
\end{tabular}

demonstrated a prevalence around 1.3\% [2]-[5]. Meanwhile, several studies have shown that only $50 \%$ of coronary anomalies identified in CT studies are identified by catheterism [6] [7].

The most common variant was myocardial bridging of the left anterior descending artery, corresponding to $69 \%$ (58/84) of all anomalies and variants described, and a prevalence of about 9\% (58/663). This result was similar to those described in series based on MSCT coronary angiographic studies [12] [16], but less than those described in autopsy series, in which the prevalence ranges from $16 \%$ to $80 \%$.

Origin anomalies prevalence was about $2 \%$, higher than the one described in a study in the Portuguese population based cardiac catheterization studies: $0.54 \%$ [5]. The anomalous origin in the contralateral sinus was the most common origin anomaly, with a prevalence of $0.9 \%$ (6/663), most commonly the right coronary artery, similar to other series based on tomography studies [6] [13]-[15] and some based on catheterism [17]. In some studies, the anomalous origin of the circumflex artery was the most frequent origin anomaly [1] [3]. In some series based in cardiac catheterization, the absence of a left coronary artery, with separated origin of the anterior descending artery and circumflex arteries was the most common origin anomaly [2] [5], this may be due to an overestimation in the cardiac catheterization studies, caused by the presence of a short left coronary stem.

Some CVA are considered malignant as they have an increased risk of sudden death, [2] [18]. Four abnormalities were identified as malignant in our study: all corresponding to an anomalous origin in the contralateral sinus, with an interarterial path. This is indeed the most common malignant anomaly described in the literature [2] [5] [13] [14] [18].

A case of single coronary artery was also identified, a very rare anomaly, corresponding to a prevalence of $0.15 \%(1 / 663)$ in our population. In the literature, the reported prevalence is lower $(0.024 \%)$ [19] [20], which is mainly due to the small size of our population. The single artery identified was classified as $\mathrm{R}$ (origin from the right coronary sinus), group III: separate origin of the ADA and the CCA, which held a retroaortic course [20].

Some anomalies were not found: origin in the pulmonary artery, arcade and extra heart termination, all very rare. Pulmonary artery origin is usually associated with death in the first year of life (childhood type), but there is also described an adult type [21].

\section{Conclusion}

MSCT coronary angiographic studies are able to identify and characterize effectively anomalies and variations of the coronary arteries, including those associated with an increased risk of sudden death (malignant) and are the actual first line imaging study. The prevalence of anomalies and variations of the coronary arteries in our sample was higher than the series based on cardiac catheterization, and comparable to the series based on tomography.

\section{References}

[1] Barriales-Villa, R., Morís, C., Sanmartín, J.C., Fernández, E., Pajín, F. and Nodar, R. (2006) Registro de anomalías congénitas de las arterias coronarias con origen en el seno de Valsalva contralateral en 13 hospitales españoles (RACES). Revista Española de Cardiología, 59, 620-623. http://dx.doi.org/10.1157/13089750 
[2] Yamanaka, O. and Hobbs, R.E. (1990) Coronary Artery Anomalies in 126,595 Patients Undergoing Coronary Arteriography. Catheterization and Cardiovascular Diagnosis, 2, 28-40. http://dx.doi.org/10.1002/ccd.1810210110

[3] Barriales-Villa, R., Morís, C., Lopez-Muñiz, A., Hernandez, L.C. and San-Roman, L. (2001) Adult Congenital Anomalies of the Coronary Arteries Described over 31 Years of Angiographic Studies in the Asturias Principality: Main Angiographic and Clinical Characteristics. Revista Española de Cardiología, 54, 269-281.

[4] Angelini, P. (2007) Coronary Artery Anomalies: An Entity in Search of an Identity. Circulation, 115, 1296-1305.

[5] Correia, E., Ferreira, P., Rodrigues, B., Santos, L., Faria, R., Nunes, R., Pipa, J., et al. (2010) Prevalence of Anomalous Origin of Coronary Arteries: A Retrospective Study in a Portuguese Population. Revista Portuguesa de Cardiologia, 29, 221-229.

[6] Shi, H., Aschoff, A.J., Brambs, H.J. and Hoffmann, M.K.. (2004) Multislice CT Imaging of Anomalous Coronary Arteries. European Radiology, 14, 2172-2181. http://dx.doi.org/10.1007/s00330-004-2490-2

[7] Schmitt, R., Froehner, S., Brunn, J., Wagner, M., Brunner, H., Cherevatyy, O., et al. (2005) Congenital Anomalies of the Coronary Arteries: Imaging with Contrast-Enhanced, Multidetector Computed Tomography. European Radiology, 15, 1110-1121. http://dx.doi.org/10.1007/s00330-005-2707-z

[8] Alemañ, G.B., Burgos, A., Agüero, P.M., Rodrígues, C.S., Villoslada, J.C.P. and Ezquerra, A. (2008) Normal Anatomy, Anatomical Variants, and Anomalies of the Origin and Course of the Coronary Arteries on Multislice CT. Radiología, 50, 197-206.

[9] Shriki, J.E., Shinbane, J.S., Rashid, M.A., Hindoyan, A., Withey, J.G., DeFrance, A., et al. (2012) Identifying, Characterizing, and Classifying Congenital Anomalies of the Coronary Arteries. RadioGraphics, 32, 453-468. http://dx.doi.org/10.1148/rg.322115097

[10] Kim, S.Y., Seo, J.B., Do, H.H., Heo, J.N., Lee, J.S., Song, J.W., et al. (2006) Coronary Artery Anomalies: Classification and ECG-Gated Multi-Detector Row CT Findings with Angiographic Correlation. RadioGraphics, 26, 317-334. http://dx.doi.org/10.1148/rg.262055068

[11] Bazzocchi, G., Romagnoli, A., Sperandio, M. and Simonetti, G. (2011) Evaluation with 64-Slice CT of the Prevalence of Coronary Artery Variants and Congenital Anomalies: A Retrospective Study of 3236 Patients. La Radiologia Medica, 116, 675-689. http://dx.doi.org/10.1007/s11547-011-0627-3

[12] Cademartiri, F., La Grutta, L., Malagò, R., Alberghina, F., Meijboom, W.B., Pugliese, F., et al. (2008) Prevalence of Anatomical Variants and Coronary Anomalies in 543 Consecutive Patients Studied with 64-Slice CT Coronary Angiography. European Radiology, 18, 781-791.

[13] Rodríguez-Granillo, G.A., Rosales, M.A., Pugliese, F., Fernández-Pereira, C. and Rodríguez, A.E. (2009) Prevalence and Characteristics of Major and Minor Coronary Artery Anomalies in an Adult Population Assessed by Computed Tomography Coronary Angiography. Eurointervention, 4, 641-617. http://dx.doi.org/10.4244/EIJV4I5A107

[14] Almeida, C., Dourado, R., Machado, C., Santos, E., Pelicano, N., Pacheco, M., et al. (2012) Anomalias das artérias coronárias. Revista Portuguesa de Cardiologia, 31, 477-494. http://dx.doi.org/10.1016/j.repc.2012.05.001

[15] Shabestari, A.A., Akhlaghpoor, S., Tayebivaljozi, R. and Fattahi, M.F. (2012) Prevalence of Congenital Coronary Artery Anomalies and Variants in 2697 Consecutive Patients Using 64-Detector Row Coronary CT-Angiography. Iranian Journal of Radiology, 9, 111-121. http://dx.doi.org/10.5812/iranjradiol.8070

[16] Möhlenkamp, S., Hort, W., Ge, J. and Erbel, R. (2002) Update on Myocardial Bridging. Circulation, 106, $2616-2622$. http://dx.doi.org/10.1161/01.CIR.0000038420.14867.7A

[17] Angelini, P., Velasco, J.A. and Flamm, S. (2002) Coronary Anomalies Incidence, Pathophysiology, and Clinical Relevance. Circulation, 105, 2449-2454. http://dx.doi.org/10.1161/01.CIR.0000016175.49835.57

[18] Pinho, T., Leta, R., Carreras, F., Alomar, X. and Pons-Lladó, G. (2006) Avaliação das Anomalias de Origem das Artérias Coronárias com Tomografia Cardíaca Computorizada. Revista Portuguesa de Cardiologia, 25, 641-645.

[19] Zhu, J., Qin, X.G., Wu, Q.Y., Xiong, W.G., Lu, C.P. and Wang, R.F. (2011) Single Coronary Artery Anomaly: The Left Main Coronary Artery Originating from the Proximal Segment of Right Coronary Artery. Chinese Medical Journal, 124, 956-995.

[20] Lipton, M.J., Barry, W.M., Obrez, I., Silverman, J.F. and Wexler, L. (1979) Isolated Single Coronary Artery: Diagnosis, Angiographic Classification, and Clinical Significance. Radiology, 130, 39-47.

[21] Khanna, A., Torigian, D.A., Ferrari, V.A., Bross, R.J. and Rosen, M.A. (2005) Anomalous Origin of the Left Coronary Artery from the Pulmonary Artery in Adulthood on CT and MRI. AJR, 185, 326-329. http://dx.doi.org/10.2214/ajr.185.2.01850326 
C. A. Oliveira et al.

\section{Abbreviations}

CVA Coronary Variants and Anomalies

LCX Left Circumflex

ECG Electrocardiogram

LAD Left Anterior Descending

LC Left Coronary

MSCT Multislice Computed Tomography

RC Right Coronary 